Huminicki, D.M.C. \& Hawthorne, F.C. (2002): The crystal chemistry of phosphate minerals. Reviews in Mineralogy and Geochemistry 48, 123-253.

Ventruti G., Monno A., Schingaro E., Lacalamita M., Della Ventura G., Bellatreccia F., Cuocci C.. Capitelli F. Structure refinement and vibrational spectroscopy of vauxite from the type locality, Lallagua (Bolivia). Canadian Mineralogist, in press.

Libowitzky, E. (1999): Correlation of O-H stretching frequencies and $\mathrm{O}-\mathrm{H} . . \mathrm{O}$ hydrogen bond lengths in minerals. Monatshefte für Chemie 130, 1047-1059.

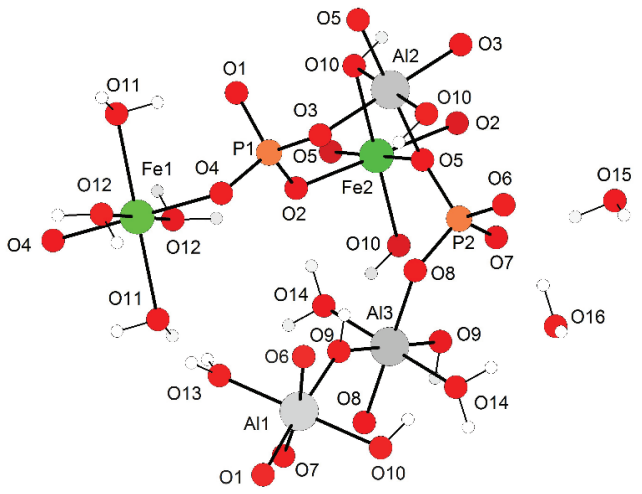

Figure 1. Cationic and anionic environments for vauxite.

Keywords: phosphates; structure refinement; hydrogen bonds; FTIR

\section{MS19-P2 Constructing new porous materials based on polymeric cage metallosiloxanes}

Alexander A. Korlyukov ${ }^{1}$, Anna V. Volozhanina ${ }^{1}$, Olga I.

Shchegolikhina ${ }^{1}$, Alexei N. Bilyachenko ${ }^{1}$, Boris G. Zavin ${ }^{1}$, Nataliya V. Sergienko ${ }^{1}$

1. A.N. Nesmeyanov Institute of Organoelement Compounds, 119991, Russian Federation, Moscow, Vavilova Str., 28

email: alex@xrlab.ineos.ac.ru

We report on structural features and electronic properties of polymeric metallasiloxanes obtained by X-ray studies, magnetic measurements and theoretical calculations. Polymer structure of metallasiloxanes (MOS) under discussion composed from cage monomeric units containing various number of transition metals $(\mathrm{Cu}$, $\mathrm{Ni}, \mathrm{Mn}, \mathrm{Fe}$ ) interconnected by alkali-metal ions and weak interatomic interactions (hydrogen bonds or staking interactions). The type of supramolecular architecture $(1 \mathrm{D}, 2 \mathrm{D}$ or $3 \mathrm{D}$, see Figure 1) can be controlled by variation of ionic radii of alkali metal, the nature of solvent used for crystallization and addition of chelating ligands. These factors also affect the size of MOS monomeric units which can include 2-11 transition metal atoms forming metalloxide core partially coated by cyclic and acyclic siloxanolate ligands. Magnetic measurements have shown the pronounced ferro- and antiferromagnetic properties depending on number and the nature of transition metal in MOS core.

It was demonstrated by powder X-ray diffraction (XRD) and XAFS studies that polymer structure established at low temperature by single crystal XRD in the most of cases retained at room temperature. The role of metallosiloxanes as structure building units, the topology of resulting nets and accessibility of the voids were analyzed. In addition, the strength of coordination bonds and weak interatomic interactions responsible for the stabilization of polymer structures were estimated in terms of R. Bader's QTAIM theory.

Authors are grateful to Prof. Yan Zubavichus (Kurchatov Center for Synchrotron Radiation and Nanotechnology) for help with XAFS and single-crystal synchrotron studies. The work was supported by Russian Science Foundation (grant 14-23-00231).
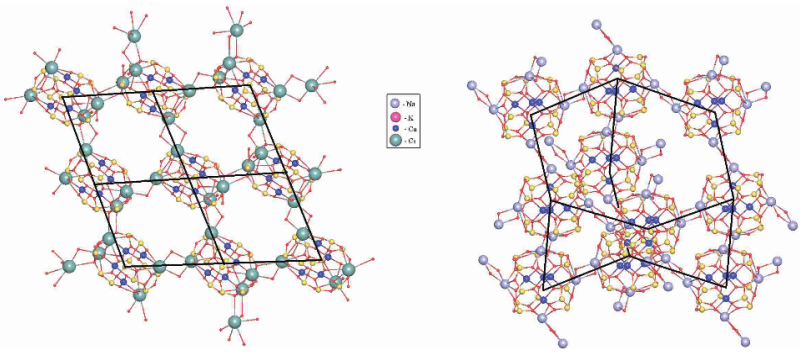

Figure 1. Fragments of the sql and dia nets in the structures of sodium (left) and cesium (right) coppersiloxanes

Keywords: metallasiloxanes, coordination polymers, structure building unit, magnetic properties, QTAIM studies. 